\title{
Detection of anomalies in the UV-vis reflectances from the Ozone Monitoring Instrument
}

\author{
Nick Gorkavyi ${ }^{1}$, Zachary Fasnacht ${ }^{1}$, David Haffner ${ }^{1}$, Sergey Marchenko ${ }^{1}$, Joanna Joiner $^{2}$, and Alexander Vasilkov ${ }^{1}$ \\ ${ }^{1}$ Science Systems and Applications, Lanham, MD, USA \\ ${ }^{2}$ National Aeronautics and Space Administration (NASA), Goddard Space Flight Center (GSFC), Greenbelt, MD, USA
}

Correspondence: Nick Gorkavyi (nick.gorkavyi@ssaihq.com)

Received: 12 August 2020 - Discussion started: 25 August 2020

Revised: 11 December 2020 - Accepted: 18 December 2020 - Published: 8 February 2021

\begin{abstract}
Various instrumental or geophysical artifacts, such as saturation, stray light or obstruction of light (either coming from the instrument or related to solar eclipses), negatively impact satellite measured ultraviolet and visible Earthshine radiance spectra and downstream retrievals of atmospheric and surface properties derived from these spectra. In addition, excessive noise such as from cosmic-ray impacts, prevalent within the South Atlantic Anomaly, can also degrade satellite radiance measurements. Saturation specifically pertains to observations of very bright surfaces such as sunglint over open water or thick clouds. When saturation occurs, additional photoelectric charge generated at the saturated pixel may overflow to pixels adjacent to a saturated area and be reflected as a distorted image in the final sensor output. When these effects cannot be corrected to an acceptable level for science-quality retrievals, flagging of the affected pixels is indicated. Here, we introduce a straightforward detection method that is based on the correlation, $r$, between the observed Earthshine radiance and solar irradiance spectra over a $10 \mathrm{~nm}$ spectral range; our decorrelation index (DI for brevity) is simply defined as a DI of $1-r$. DI increases with anomalous additive effects or excessive noise in either radiances, the most likely cause in data from the Ozone Monitoring Instrument (OMI), or irradiances. DI is relatively straightforward to use and interpret and can be computed for different wavelength intervals. We developed a set of DIs for two spectral channels of the OMI, a hyperspectral pushbroom imaging spectrometer. For each OMI spatial measurement, we define 14 wavelength-dependent DIs within the OMI visible channel $(350-498 \mathrm{~nm})$ and six DIs in its ultraviolet 2 (UV2) channel (310-370 nm). As defined, DIs reflect a continuous range of deviations of observed spec-
\end{abstract}

tra from the reference irradiance spectrum that are complementary to the binary saturation possibility warning (SPW) flags currently provided for each individual spectral or spatial pixel in the OMI radiance data set. Smaller values of DI are also caused by a number of geophysical factors; this allows one to obtain interesting physical results on the global distribution of spectral variations.

\section{Introduction}

The Ozone Monitoring Instrument (OMI) is a Dutch/Finnish ultraviolet (UV) and visible (vis) wavelength spectrometer that is aboard NASA's Aura satellite which was launched on 15 July 2004. It has provided $1-2 \mathrm{~d}$ of global coverage for several important atmospheric trace gases including ozone $\left(\mathrm{O}_{3}\right)$, sulfur dioxide $\left(\mathrm{SO}_{2}\right)$, nitrogen dioxide $\left(\mathrm{NO}_{2}\right)$ and formaldehyde ( $\mathrm{HCHO}$ ), as well as information about clouds and aerosols (Levelt, 2002; Levelt et al., 2018). OMI has contributed to studies of atmospheric pollution, climate-related agents and stratospheric chemistry (Levelt et al., 2018); led to the first observation of glyoxal $\left(\mathrm{C}_{2} \mathrm{H}_{2} \mathrm{O}_{2}\right)$ from space (Chan Miller et al., 2014); and provided precise long-term records of solar spectral irradiances (Marchenko and Deland, 2014). OMI's data have contributed to medium-range weather and air quality forecasts, as well as to detection and tracking of volcanic plumes (Hassinen et al., 2008; Krotkov et al., 2015; Levelt et al., 2018). OMI measurements also provide estimates of tropospheric ozone columns (e.g., Sellitto et al., 2011; Ziemke et al., 2017). Several similar sensors are currently in orbit, including the Tropospheric Monitoring Instrument (TROPOMI) aboard the Copernicus Sentinel-5 precur- 
sor (S5P) satellite, Ozone Mapping and Profiler Suite/Nadir Mapper (OMPS/NM) on the Suomi National Polar-Orbiting Partnership (Suomi NPP) and National Oceanic and Atmospheric Administration (NOAA)-20, and Global Ozone Monitoring Experiment 2 (GOME-2) instruments on European Organisation for the Exploitation of Meteorological Satellites (EUMETSAT) MetOp platforms.

Non-linear effects can impact the measured signal when not properly corrected. This can degrade Earthshine radiance measurements from passive solar backscatter UV-vis satellite spectra and thus impact retrievals of atmospheric constituents and surface properties. There are several potential sources for these effects. Saturation occurs when bright light causes the number of electrons in a sensor pixel to exceed either the maximum charge capacity of an individual chargecoupled device (CCD) photodiode or the maximum charge transfer capacity of the sensor. Blooming and other artifacts related to charge transfer on the $\mathrm{CCD}$ may also affect the quality of the measured spectrum when electrons from a saturated pixel overflow to a neighboring pixel, causing distortion of its signal and frequently rendering affected data useless. Charge transfer and readout errors can also result in a distorted spectra, as can be the case with an error in correction for detector smear. Hereafter, we refer to the spatial domain of the two-dimensional CCD as rows (30 or 60 simultaneously acquired scenes) and the spectral domain as columns. Per OMI design, the CCD readout is in spatial pixels more easily, and therefore the blooming or charge readout-related effects are expected to predominantly occur between different spatial rows.

Retrievals of atmospheric gases or aerosols can be compromised when observing very bright surfaces such as sunglint in low-wind-speed conditions (Cox and Munk, 1954; Kay et al., 2009; Butz et al., 2013; Feng et al., 2017), as well as over scenes predominantly covered by optically thick clouds. Saturation caused by sunglint routinely occurs in the visible imagery of the MODerate Resolution Imaging Spectroradiometer (MODIS) flying on NASA's Aqua and Terra satellites. MODIS data show a gradual increase of saturated data towards the red and near-infrared (NIR) bands, reaching around 1500 pixels, or $\sim 0.03 \%$ of pixels, in a granule at $869 \mathrm{~nm}$ (Singh and Shanmugam, 2014). The Orbiting Carbon Observatory-2 (OCO-2) and similar greenhouse gas monitoring instruments occasionally point directly at the sunglint. The OCO-2 in-orbit checkout activities revealed an unexpectedly high signal from Lake Maracaibo, Venezuela, on 7 August 2014. This signal saturated all three channels and was attributed to an oil slick on a wave-free lake. After this event, known as the "Lake Maracaibo saturation incident", an automated saturation warning algorithm was incorporated into the OCO-2 processing to identify such events (Crisp et al., 2017). Solar glint from ocean and clouds, as well as "saturation tails" or blooming effects are seen in many images from the Earth Polychromatic Imaging Camera on the Deep Space Climate Observatory (EPIC/DSCOVR) (Varnai et al., 2019). TROPOMI also experiences detector saturation and blooming problems, typically caused by bright tropical clouds seen in bands $4(400-499 \mathrm{~nm})$ and $6(725-786 \mathrm{~nm})$. Bands 7 (2300-2343 nm) and 8 (2342-2389 nm) react mostly negatively to sunglint. Currently, blooming areas are not detected by the TROPOMI L0-1b processor. A flagging algorithm is under development (Rozemeijer and Kleipool, 2019; Ludewig et al., 2019).

A set of 16 operational flags, called the saturation possibility warning (SPW) flags, is currently included in the OMI level-1b data set. SPWs are designed to flag OMI pixels with 16 various radiation anomalies (e.g., saturation, stray light, non-linearity). These flags are defined for each OMI wavelength: 751 wavelengths of the vis spectrum and 557 wavelengths of the UV2 spectrum (GDPS, 2006). All of the 16 SPW flags are binary; a pixel with any degree of abnormality (e.g., saturation) at a given wavelength is marked as possibly bad.

Here, we describe a new approach to identify potentially erroneous OMI data based on the correlation $r$ between the observed backscattered Earthshine spectrum and a reference solar spectrum computed over limited spectral regions. Earthshine spectra differ from the solar spectra due to Rayleigh, rotational Raman, aerosol and surface scattering, as well as absorption of radiation by ozone and other atmospheric components. Most of these factors, with the exception of strong ozone absorption in the UV, amount to secondary effects on the correlation coefficient between the solar and Earthshine spectra within a limited spectral window. Under normal conditions (lack of detectable instrumentimposed spectral distortions) and for a reasonably narrow (5-10 nm, for practical purposes, with a moderate-resolution spectral instrument) spectral window, the degree of correlation depends mainly (but not exclusively) on the number and strength (depth) of solar Fraunhofer features, once we take into consideration additional factors (differences in spectral resolution, finite signal-to-noise ratio of measurements, misalignment of the wavelength grids, among others) that tend to degrade the correlation. In the windows with well-defined solar absorption spectral features, the correlation coefficient may gradually approach unity for the scenes acquired with $S / N \gg 100$ - a condition met in a majority of OMI UV2-vis reflectance spectra. Assuming the radiances and irradiances have the same spectral resolution and comparable $S / N$, and are closely co-aligned in the wavelength domain, the correlation coefficient between the Earthshine and the solar "etalon" (assumed to be distortion free) should be highly sensitive to any distortions in the former, leading to rapidly decreasing correlation in saturated scenes (solar glint or bright clouds) or under other anomalous conditions, such as cosmic-ray hits on the detector.

We apply our approach to OMI data and analyze individual cases and global distributions of flagged data. While these effects have been known for some time and dealt with, to some extent, the prevalence of the different effects globally 
for a particular instrument has rarely been documented. This work provides a detailed analysis of spectrum-distorting effects in the OMI case, as well as a general and straightforward approach that may be applied to similar instruments (TROPOMI, OMPS, GOME-2, etc.) to identify and filter out suspect or erroneous data.

\section{Data and methods}

\subsection{The Ozone Monitoring Instrument}

The Aura satellite that hosts OMI is in a polar Sunsynchronous orbit with a local Equator crossing time of 13:45 LT. OMI is a nadir-looking, pushbroom UV-vis grating spectrometer (Levelt et al., 2018). The light entering the telescope is depolarized using a scrambler and then split into two channels: the UV (wavelength range 264-383 nm) and the vis (wavelength range 349-504 nm; Dobber et al., 2006; Schenkeveld et al., 2017). The UV channel is further divided into the two subchannels: UV1 $(264-311 \mathrm{~nm}, 0.63 \mathrm{~nm}$ resolution and $0.21 \mathrm{~nm}$ sampling) and UV2 (307-383 nm range, $0.42 \mathrm{~nm}$ resolution with $0.14 \mathrm{~nm}$ sampling). Measurements are collected on two-dimensional CCD sensors used for the $\mathrm{UV}$ and vis channels. Spectral information is dispersed along one dimension of each CCD and spatial is imaged on the other. Each channel has a devoted frame-transfer CCD detector with $6 \times 10^{5}$ electrons/pixel full-well capacity. To avoid blooming and ellipsoid effects, the pixel filling should be kept below $3 \times 10^{5}$ electrons (Dobber et al., 2006). OMI also measures the solar irradiance once per day through the solar port. Here, we use the UV2 subchannel and vis channel only; in the UV1 channel, strong, variable ozone absorption renders our approach impractical.

In the global mode, each orbit spans the pole-to-pole sunlit portion, typically comprising 1644 along-orbit exposures, referred to as iTimes hereafter. The $114^{\circ}$ viewing angle of the telescope corresponds to a $2600 \mathrm{~km}$ wide swath on the Earth's surface and consists of 60 simultaneously acquired rows or ground pixels across the track. In this mode, the OMI pixel size is $13 \times 24 \mathrm{~km}^{2}$ at nadir. The in-flight performance of OMI is discussed in Schenkeveld et al. (2017). The radiometric degradation of the OMI radiances since launch ranges from $\sim 2 \%$ in the UV channel to $\sim 0.5 \%$ in the vis channel, which is much lower than any similar sensor (Levelt et al., 2018). One major anomaly has occurred with OMI, the socalled row anomaly (Schenkeveld et al., 2017); it is presumably caused by a partial detachment of insulation material exterior to the instrument and produces a number of anomalous effects on Sun-normalized radiances. The row anomaly is discussed in detail in Sect. 3.4.

\subsection{The decorrelation index (DI)}

We introduce a new parameter, the decorrelation index (DI), which is defined as $1-r$, where $r$ is the Pearson correlation coefficient:

$$
\mathrm{DI}=1-r=1-\frac{\sum_{i=1}^{n}\left(x_{i}-\bar{x}\right)\left(y_{i}-\bar{y}\right)}{\sqrt{\sum_{i=1}^{n}\left(x_{i}-\bar{x}\right)^{2}} \sqrt{\sum_{i=1}^{n}\left(y_{i}-\bar{y}\right)^{2}}},
$$

with $\bar{x}$ (same for $\bar{y}$ )

$\bar{x}=\frac{1}{n} \sum_{i=1}^{n} x_{i}$.

In Eqs. (1) and (2), $x_{i}$ and $y_{i}$ are the individual sample points for radiance $I$ and irradiance $F_{0}$, respectively. DI is derived for radiances and irradiances at each spectral region: for OMI, 14 regions of $\sim 10 \mathrm{~nm}(n=51$ wavelengths for each spectral region) in the vis channel and six regions of $\sim 10 \mathrm{~nm}$ ( $n=69$ wavelengths for each region) in UV2. For the standard solar spectrum or reference irradiance, we take an average of all solar spectra obtained by OMI in 2005. Each Earthshine spectrum is regridded via linear interpolation to match the wavelengths of the averaged irradiance spectrum. An exact match between the radiance and irradiance spectral features gives a DI of 0 , whereas when the features in the radiance and irradiance spectra deviate, the DI approaches 1 to 2 , where values greater than 1 indicate that irradiance and radiance spectra exhibit anti-correlation. Hence, cases of DI $>0$ may indicate distortions of atmospheric spectra. Evidently, DI is 0 for the simple case of a perfect match with $I=$ const $\times F_{0}$; if $I=-$ const $\times F_{0}$, then DI is 2 . If $I$ and $F_{0}$ are completely unrelated, then DI is 1 . Considering the "smooth" (low-frequency) component of $I$ and $F_{0}$, we expect them to be generally correlated in the spectral regions relatively free of major atmospheric absorptions (ozone in particular). The correlation would be inevitably diminished by the wavelength-dependent Rayleigh scattering and surface reflectivity. Once a multitude of deep spectral lines is superimposed on a smooth envelope, DI will depend mainly on a match between the shape and position of these $I$ and $F_{0}$ spectral transitions, with the correlation depending on the $S / N$ of the tested radiances and irradiances, and even more so on slight (in OMI's case) wavelength misalignments between radiances and irradiances, with the steep line flanks magnifying the differences.

An additional decorrelating factor is brought forth by the omnipresent atmospheric rotational Raman scattering (e.g., Joiner et al., 1995). Under the circumstances, one may never expect DI of 0 , save the exceedingly rare cases of a perfect solar glint. It is known that Pearson's correlation coefficient is sensitive to outliers, thus simplifying detection of spectral distortions in the high-resolution data compared to the lowresolution cases, with the latter tending to lessen the impact of additive components (the shallower lines are potentially less susceptible to stray light), as well as the wavelength misalignment (spectral blending of multiple features leading to 
partial canceling of distortions in the adjacent features). At a given spectral resolution and $S / N$, DI sensitivity may grow with increasing numbers and contrasts (depths) of spectral features in the chosen spectral window. At the same time, the DI is expected to be sensitive to artifacts associated with cosmic-ray hits. The interval $440-480 \mathrm{~nm}$, where there are few deep spectral lines, should be especially sensitive to geophysical factors, for example, to the wavelength-dependent albedo of the Earth's surface. Note that there are cases when direct solar radiation $F_{0}$ is mixed with $I$ due to instrument problems (see below). Under this specific circumstance, DI will decrease, since correlation between $\left(I+\delta F_{0}\right)$ and $F_{0}$ is always higher (thus, DI is lower) than between $I$ and $F_{0}$. A similar effect occurs with sunglint from the water surface, when the proportion of directly reflected sunlight in $I$ increases significantly. Note that in the current approach we do not compensate for the relatively smooth spectral differences imposed by atmospheric (Rayleigh scattering) and surface (wavelength-dependent albedo) factors, leaving this to the next DI version. This step would make DI more sensitive to the instrument-imposed anomalies, further disentangling those from the geophysical factors (see below).

In this initial version of the OMI DI, we use the spectral range 309.9-370.0 $\mathrm{nm}$ for UV2 and 349.9-498.4 $\mathrm{nm}$ for vis. Overlapping of these ranges is useful for assessing the calibration between the UV2 and VIS channels. For solar zenith angles (SZAs) $>90^{\circ}$, the radiance level drops, noise begins to dominate, and the DI grows rapidly. Therefore, we avoid SZA $>90^{\circ}$ cases. The DI is sensitive to the degree of distortion of the reflectance spectrum, regardless of the cause of the distortion (saturation, crosstalk, noise, etc.), so that it detects distortions other than saturation. For example, the DI may detect electronic cross-talk (or blooming) effects in pixels adjacent to the saturated area. In a number of cases, the DI proves to be either more or less sensitive than the current SPW flags reported in the OMI pixel quality flags filed of the level-1b data, as shown in the next section.

The DI provides a range of values that describes the deviation of observed spectra from the reference irradiance spectrum, while the SPW flag is a binary value. The DI therefore allows flexibility in setting detection thresholds for damaged spectra for different applications. The DI value for a given spectral interval depends strongly on the number of Fraunhofer lines as well as presence of strong ozone absorption features within the wavelength range. Therefore, the DI values corresponding to likely damaged spectra vary somewhat for each spectral region. For example, the 14 DI divisions of the vis spectrum generally fall into two distinct groups; for the first group, the value of DI above $0.01-0.03$ is a sign of a significant distortion of the spectrum, while for the second group a typical distortion threshold value is larger $(\sim 0.1-$ 0.4 ). The provisional (the user may redefine the values using the auxiliary data provided in the OMI DI product) DI thresholds were determined as follows. We used all available, mission-long OMI UV2 and vis radiances. For each orbit and for every spectral window, we constructed DI histograms. Then we selected numerous cases sampling the tails of the DI histograms. On a case-by-case basis, for different scenes and spectral windows, we found empirically the lowest DI values that repeatedly separate the scenes with apparently normal (spectrally smooth, with the fine-structure, low-amplitude Raman-scattering features) and distorted reflectances. These DI thresholds approximately correspond to the 99.995-99.998 percentiles in the DI distributions. We plan to provide a statistically rigorous threshold definition in the improved DI version.

Table 1 summarizes the DI wavelength bands and suggested threshold values corresponding to damaged spectra. These critical values should be treated as indicative. A user may define different thresholds depending on their application. We chose row 20 to determine these critical values. The dependence of the threshold DI values on cross-track position is relatively minor, except for the first UV2 interval. For this interval, other cross-track positions may carry different values, primarily due to ozone absorption (increasing towards the swath edges). The DI thresholds depend on spectral resolution and $S / N$ of the reflectances; hence, the indicative values from Table 1 may vary for different instruments.

\section{Results}

To study the DI, we first concentrate on scenes that are most likely to contain saturation effects: sunglint areas with relatively calm water surfaces and contiguous bands of deep convective clouds. Next, we examine the global DI distribution, which reveals other effects that damage observed spectra. We then investigate the impact of the row anomaly on the DI.

\subsection{Saturation over clouds}

A typical problematic cluster of bright clouds in the Pacific Ocean is shown in Fig. 1a, where two zones are highlighted, a small northern zone (denoted A) and a large southern zone (marked as B). Figure 1c shows the number of wavelengths for a given pixel marked with the SPW flag as saturated. Figure $1 \mathrm{~b}-\mathrm{d}$ show the corresponding DI values for the vis interval at $414-424 \mathrm{~nm}$. The DI indicates that the spectra in zone A are weakly affected, and in zone B they are badly damaged. Figure 1c shows the number of wavelengths for a given pixel marked with the SPW flag as saturated.

Figures 2 and 3 illustrate the properties of the DI that characterize the quality of a given part of the spectrum using a single parameter. Figure 2 shows an example of a spectrum with slight distortions that are captured by the SPW flags but nevertheless has low values of the DI. Small deviations of the DI from 0 can result from geophysical effects, for example, an increased amount of ozone, and minor damage to the spectrum, as shown in Fig. 2. Those users who have strict requirements for the quality of the spectra should use the SPW 
Table 1. Chosen OMI DI spectral intervals and indicative DI thresholds for damaged spectra.

\begin{tabular}{lrrl}
\hline $\begin{array}{l}\text { Interval } \\
(\mathrm{UV} 2)\end{array}$ & $\begin{array}{r}\text { Wavelengths (nm) } \\
\text { (for row 20) }\end{array}$ & $\begin{array}{r}\text { Value DI as signature of } \\
\text { distortion of spectra }\end{array}$ & Comments \\
\hline 1 & $309.94-320.61$ & $-^{*}$ & Strong ozone effects \\
2 & $320.76-331.08$ & $>0.20-0.25$ & Ozone effects \\
3 & $331.23-341.24$ & $>0.35-0.45$ & Weak ozone effects \\
4 & $341.39-351.11$ & $>0.02-0.03$ & Strong spectral lines \\
5 & $351.25-360.70$ & $>0.02$ & Strong spectral lines \\
6 & $360.84-370.02$ & $>0.01$ & Strong spectral lines \\
\hline$($ vis) & & & \\
\hline 1 & $349.93-360.33$ & $>0.03$ & Strong spectral lines \\
2 & $360.54-370.93$ & $>0.01$ & Strong spectral lines \\
3 & $371.14-381.52$ & $>0.02$ & Strong spectral lines \\
4 & $381.73-392.11$ & $>0.01$ & Strong spectral lines \\
5 & $392.32-402.70$ & $>0.06-0.08$ & \\
6 & $402.91-413.29$ & $>0.1-0.15$ & \\
7 & $413.50-423.89$ & $>0.02-0.03$ & Strong spectral lines \\
8 & $424.10-434.50$ & $>0.05-0.1$ & \\
9 & $434.71-445.12$ & $>0.25$ & \\
10 & $445.32-455.74$ & $>0.4$ & \\
11 & $455.95-466.39$ & $>0.4$ & \\
12 & $466.60-477.05$ & $>0.2$ & Strong spectral lines \\
13 & $477.26-487.72$ & & \\
14 & $487.93-498.41$ & & \\
\hline
\end{tabular}

* The threshold depends on the row number.

flag in this case, which detects minor damage to the spectrum. Figure 3 shows the vis spectrum for a pixel in zone B (indicated by an arrow in Fig. 1) corresponding to iTimes 807 , row 20 . The radiance spectrum is saturated in the 400 $465 \mathrm{~nm}$ range. In contrast to Fig. 2, damage in this spectrum is manifested in both the SPW flag and the DIs. The DIs reflect the degree of spectral damage, which in this case reaches a maximum near $450 \mathrm{~nm}$. Based on the problem studied here, a user can determine whether the spectrum is useful despite minor damage such as in zone A. In such cases, the SPW and DI may provide complementary information.

Reflectance in Figs. 2 and 3 is defined as $\pi \cdot I /\left[F_{0} \cdot \cos (\theta)\right]$, where $I$ is the top-of-the-atmosphere (TOA) radiance, $F_{0}$ is the extraterrestrial solar flux, and $\theta$ is the SZA. Usually, the wavelength dependence of TOA reflectance is fairly smooth, albeit with relatively low-amplitude, high-frequency structures due to rotational Raman scattering, also known as the Ring effect. Both zones in Fig. 1 have high values of reflectance; for zone A, reflectance is between 0.95 and 1.0 (Fig. 2), while for zone B, reflectance is between 1.0 and 1.1 (Fig. 3). In some viewing directions, the reflectance can exceed unity due to anisotropic angular distribution of the TOA radiance.

\subsection{Saturation over lakes and oceans}

The South American Salar de Uyuni is a lake used for calibration of many satellite sensors (Lamparelli et al., 2003; Fricker et al., 2005). Salar de Uyuni is dry for most months of the year, but during the rainy season, it is filled with shallow water with strong direct reflectance from the Sun. This may cause saturation of OMI's detectors. The lake, covered with shallow water, generated strong solar glint, for example, for orbit 7987 (14 January 2006). Figure 4a shows this shallow lake on 14 January 2006 as observed by the Aqua MODIS sensor. The SPW flags (Fig. 4c) and DIs (Fig. 4b, d) for this case show that the lake generates two bright spots: southern and northern. The solar glint from the northern spot is so bright that the signal extends to nearby pixels (iTimes $823-825$, rows $11-14$ ) and is detected by the DI (see also Cao et al., 2019; Shen et al., 2019, for examples of blooming in other sensors). The SPW flags are unset for significant portions of the affected OMI pixels (see Fig. 4).

Figure 5 shows the vis spectrum for a pixel on the edge of the highly saturated region. This pixel may have superimposed effects of moderate saturation of the pixel itself as well as charge overflow from due to significant saturation in the neighboring pixels (iTimes 824, row 15). While the reflectance values of many of these pixels (rows $\sim 11-15$ in Fig. 4$)$ are in the expected range (0.3-0.6), there are numer- 

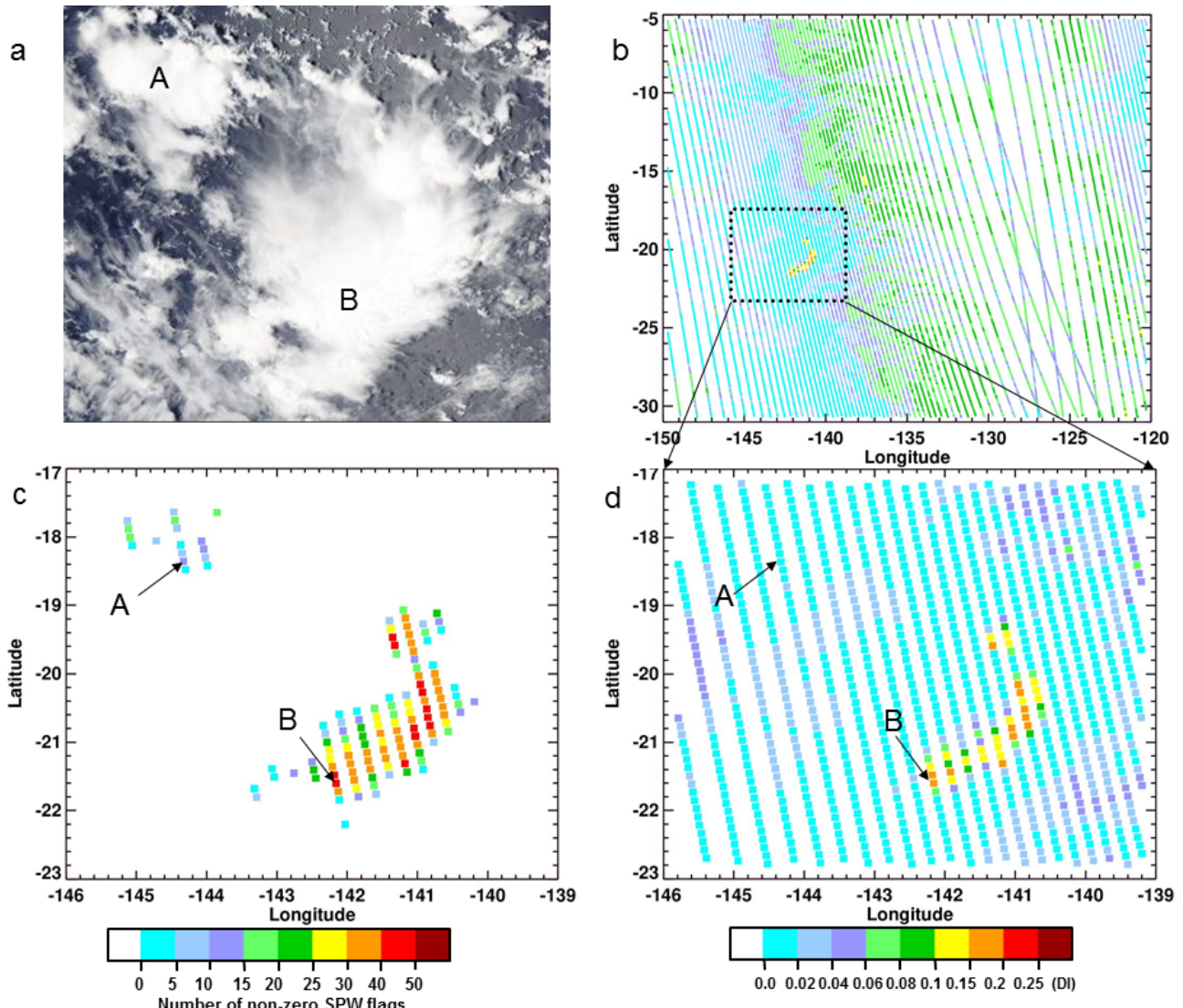

Figure 1. Two cloud zones in the south Pacific on 14 January 2006 for orbit 7990: small northern zone labeled "A" and large southern labeled "B" (a) Aqua MODIS image; (b, d) DI maps for the vis spectral region (414-424 nm); (c) the number of wavelengths for a given pixel marked with the SPW flag as saturated (the maximum number is 51 in this vis spectral region).

ous cases where the final radiance signal is well beyond normal range, thus leading to high DIs.

Figure 6 shows the spectrum of a pixel where the prevailing anomalous effect do not appear to be direct saturation (iTimes 824, row 11). High DI values are seen for a number of corrupted parts of the spectrum where the SPW flags are zero. While the saturated case is straightforward to detect and interpret (e.g., the practically featureless radiances in Figs. 3 and 4), these other spectral distortions may have a complex spectral envelope due to the differences in the wavelength sampling of the sequential OMI rows.

The completely saturated spectral domains may trigger effects in the neighboring rows, indiscriminately affecting the involved wavelengths. However, in the case of a less severely saturated scene, there might be additional effects to consider. Per instrument design, the OMI wavelength grids form a "spectral smile" in the row-wise direction. Inspecting the wavelength registration for a given CCD column (the spectral domain) while moving from the swath's edges towards nadir, one may notice gradual wavelength shifts between the adjacent rows. The wavelengths are increasing while moving from the edges to the center of the swath, thus forming a "smile". This may result in occasional augmented distortions around narrow, well-defined features in the spectral image in non-saturated pixels, while the signal for other wavelengths in the spectrum may remain intact. Such occasional distortions could be mimicked and greatly outnumbered by a different effect that also stems from the spectral smile. In some cases, brightly lit (but not saturated) scenes border low-reflectance areas: e.g., the studied Salar de Uyuni case, cloud-front edges or the edges of extended fresh snow and/or ice fields. In these bordering low-reflectance scenes, the greatly augmented spatial stray light could mimic a blooming effect caused by the spectral smile, thus leading to higher DI around strong, deep spectral transitions that may exceed the imposed threshold. In the OMI data sampling the high-contrast scenes, the spatial stray-light effects induce wavelength shifts that affect trace-gas retrievals (Richter et al., 2020). Some of the above-threshold DIs in the global maps (midlatitudes to high latitudes, open-water scenes; see below) could be triggered by the high-contrast scenario.

An example of solar glint in the Caribbean Sea is shown in Fig. 7 for 26 July 2013. Effects of the glint for this case are detected in both the DI and SPW flags. Some of the pixels 


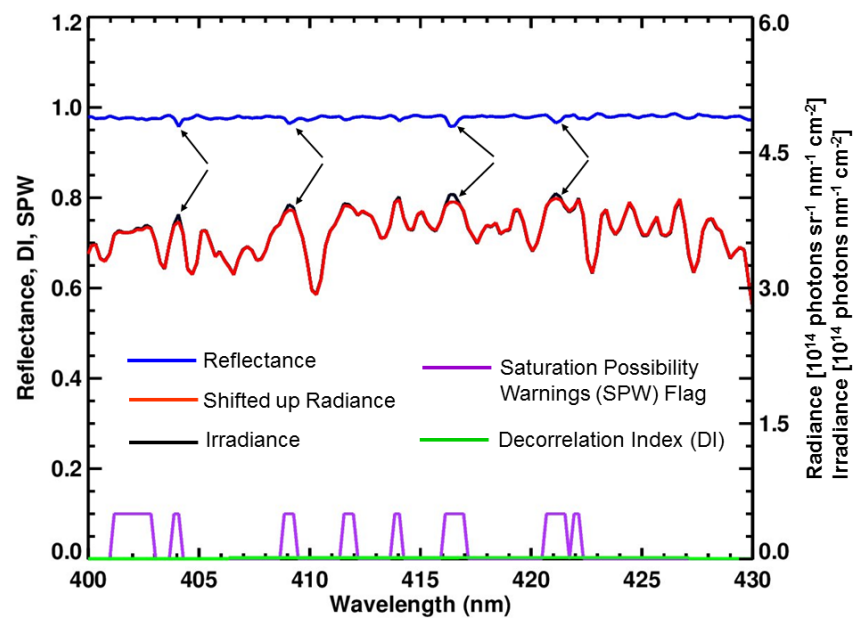

Figure 2. Data for iTimes 839, row 15, orbit 7990, 14 January 2006 in zone A (this pixel is marked by arrows in Fig. 1c, d). The blue line at the top of the picture is reflectance $\pi I /\left[F_{0} \cos (\theta)\right]$, where $\theta$ is solar zenith angle. Reflectance in this zone has slight variations caused by minor saturation in the atmospheric spectrum, as indicated by the arrows. The purple line shows the binary SPW flags multiplied by 0.1 . The green line is the DI $<0.01$ for bands $403-413,413-424$ and $424-434 \mathrm{~nm}$. The intensity of the radiance spectrum is shifted upwards slightly for clearer comparison with the irradiance spectrum.

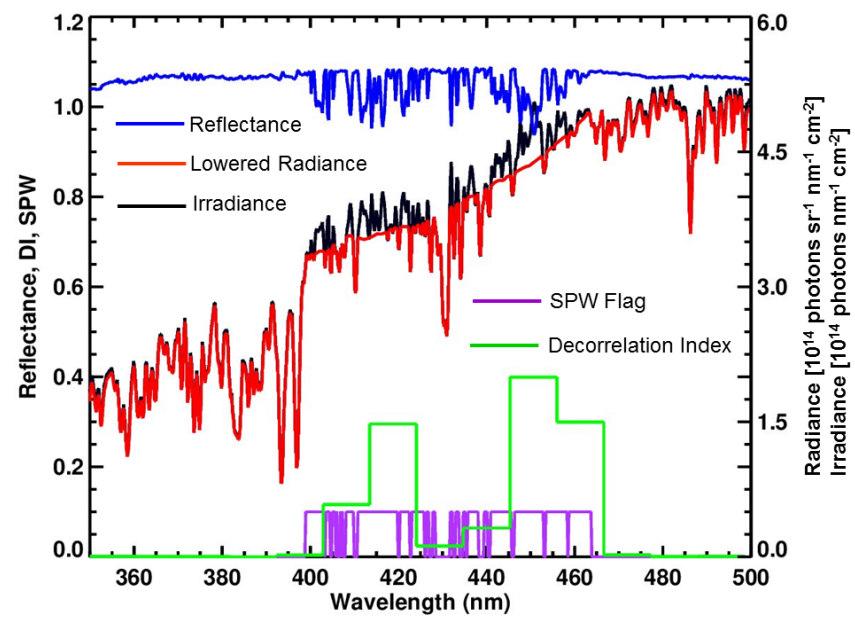

Figure 3. Similar to Fig. 2 but for iTimes 807, row 20, orbit 7990, 14 January 2006 in cloud region B (see arrows in Fig. 1c, d). The radiance was lowered by a few percent for better comparison.

not marked by the SPW flags show high DI values that may be related to blooming or other effects associated with the impaired performance of neighboring pixels on the detector.

\subsection{Orbital and global distribution}

Figures 8-10 show global distributions of the number of affected vis spectra with DI greater than thresholds for spectra for March 2006 (Figs. 8 and 9) and for all of 2006 (Fig. 10).
The global DI behavior depends on many geophysical and instrumental processes. For example, Fig. 8a shows the spatial distribution of the number of spectra with DI $>0.03$ for the $424.1-434.5 \mathrm{~nm}$ range. Figure $8 \mathrm{~b}$ similarly shows distributions for DI $>0.25$ in the $445.3-455.7 \mathrm{~nm}$ spectral window. Despite the different threshold DI values that characterize the distorted spectra, these two DIs show similar distributions of corrupted spectra associated with enhanced cosmic-ray hits on the detectors within the South Atlantic Anomaly (SAA) region, glint and a solar eclipse zone. Though we cannot disentangle the contributing factors for the latter, here we mention two of them as the likely causes of the high DI values (thus enhanced distortions in the reflectances): the low $S / N$ of the eclipsed radiances, as well as the drastically increased portion (compared to the normally lit scenes) of the additive (stray-light) component.

The interpretation of low DI for normal spectra (for example, spectra with DI $>0.1$ for vis of $445.3-455.7 \mathrm{~nm}$ ) is quite complicated as low DI values depend on many factors. Figure 9 shows the spatial distribution of the number of spectra with DI $>0.1$ in the $445.3-455.7 \mathrm{~nm}$ region compared with ocean reflectance at $443 \mathrm{~nm}$. There is obvious spatial correlation between the spectra the DI identifies and ocean reflectance: larger numbers of such spectra correspond to ocean areas with higher reflectance. This is particularly pronounced in the southern Pacific gyre whose waters exhibit extremely low bioproductivity and thus are very bright in the blue region (Tedetti et al., 2007). The strong spectral dependence of water-leaving reflectance in the blue region in these extremely clear waters results in lower correlation with the solar spectrum. This may be attributed in part to vibrational Raman scattering that is prevalent in clear ocean waters (Vasilkov et al., 2002; Westberry et al., 2013). Additionally, the Pacific gyre area is characterized by low cloudiness and low aerosol loadings. Therefore, in this area, the relatively high proportion of the shown data comes from the surface, thus being more susceptible to the Rayleigh and Raman scattering effects. These change the TOA radiances in different ways: the low-frequency spectral envelope is affected by Rayleigh, while the fine-scale structures are introduced by the vibrational and rotational Raman scattering. Both effects lead to "distorted" reflectances and thus higher DIs.

Figure 10a-b show the orbital distributions of the 445.3$455.7 \mathrm{~nm}$ DI for DI $>0.25$ and DI $>0.6$, respectively, plotted for OMI detector rows (generally oriented east-west across the satellite track) versus iTimes (north-south orbital direction) for 2006. A block of 250 along-orbit exposures (iTimes) approximately covers $30^{\circ}$ in latitude. The middle of this band falls on the Equator on 22 March. During the year, this band shifts by $22.4^{\circ}$ to both the north and south The zone around row 21 and iTimes 820 is an area of solar glint from the ocean surface (case where DI $>0.6$; Fig. 10b) that does not change with season. The distribution of bright clouds with DI $>0.25$ also shows a strong propensity for the geometrical conditions of solar glint (Fig. 10a). This is con- 
a
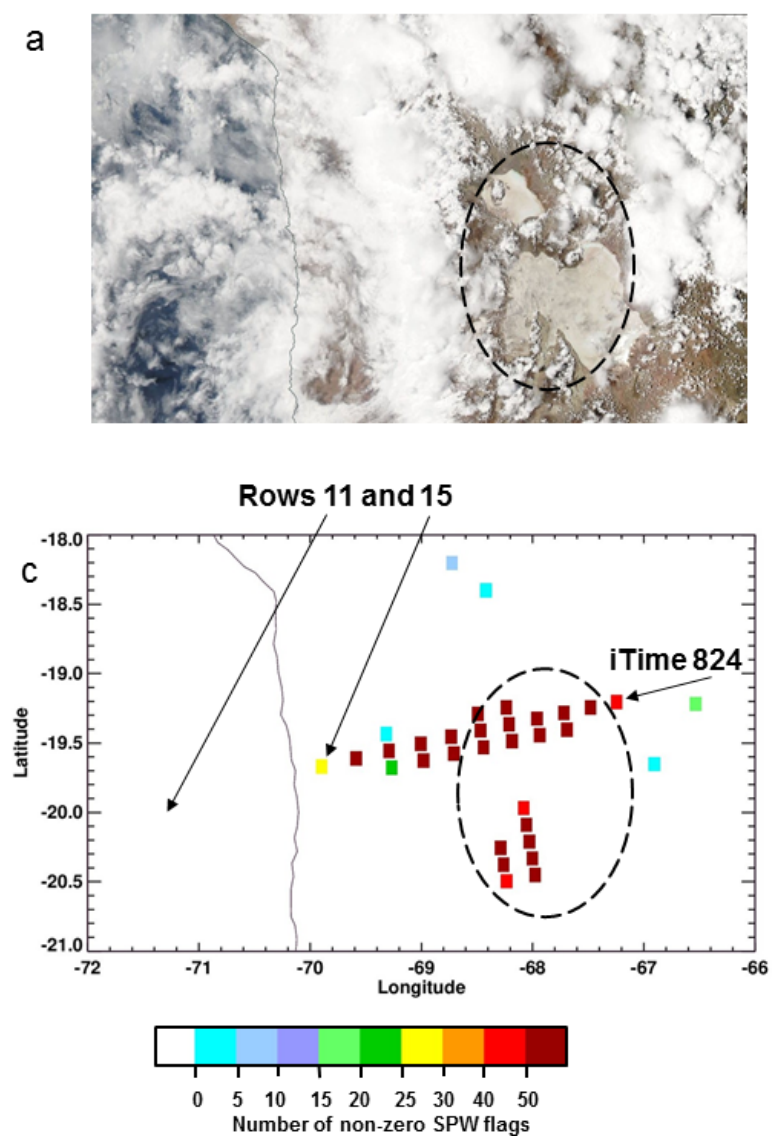

b

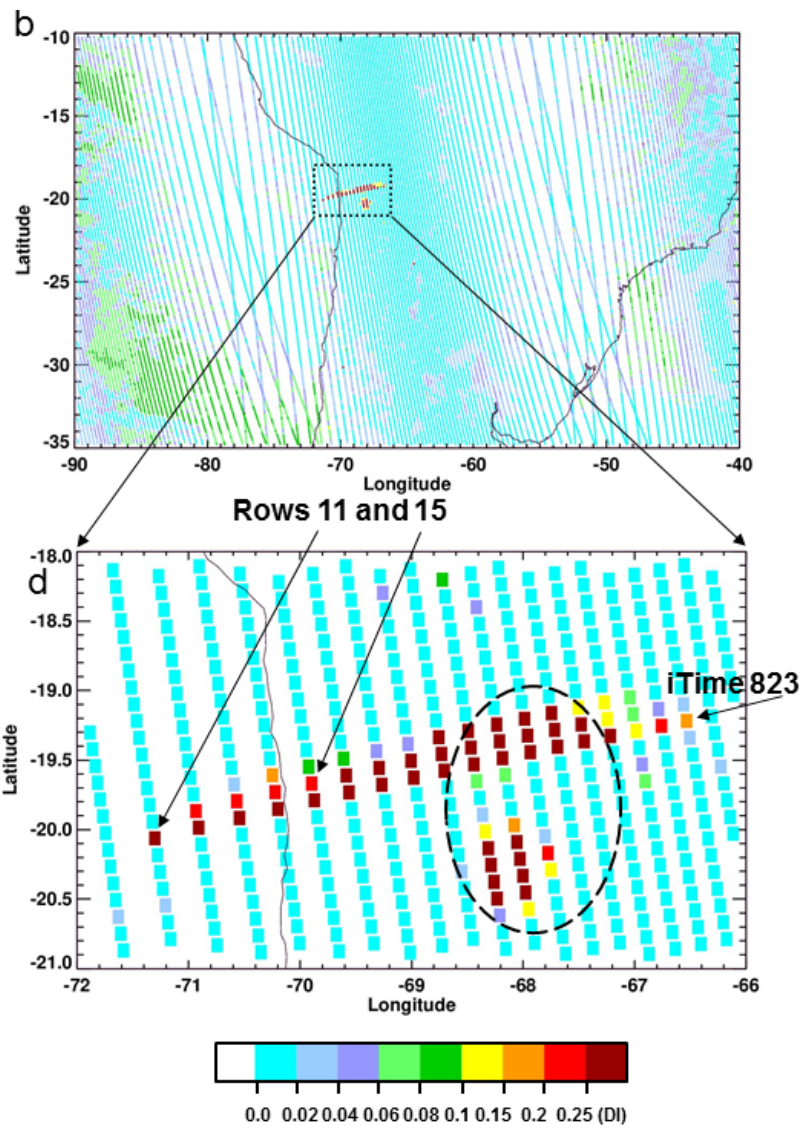

Figure 4. Similar to Fig. 1 but for an area near Salar de Uyuni, 14 January 2006, orbit 7987.

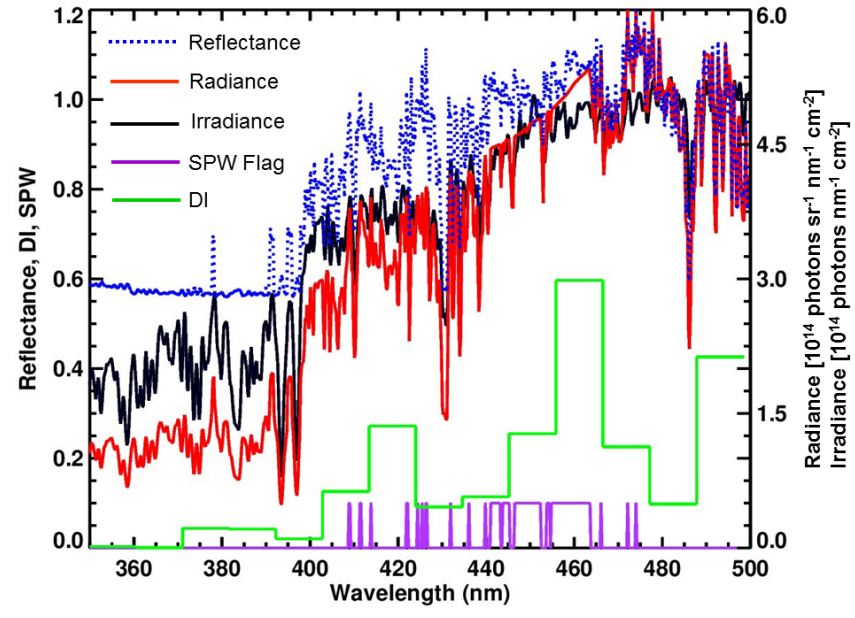

Figure 5. Similar to Fig. 2 but for pixel iTimes 824, row 15, orbit 7987 indicated by arrows in Fig. 4c, d showing solar glint from Salar de Uyuni.

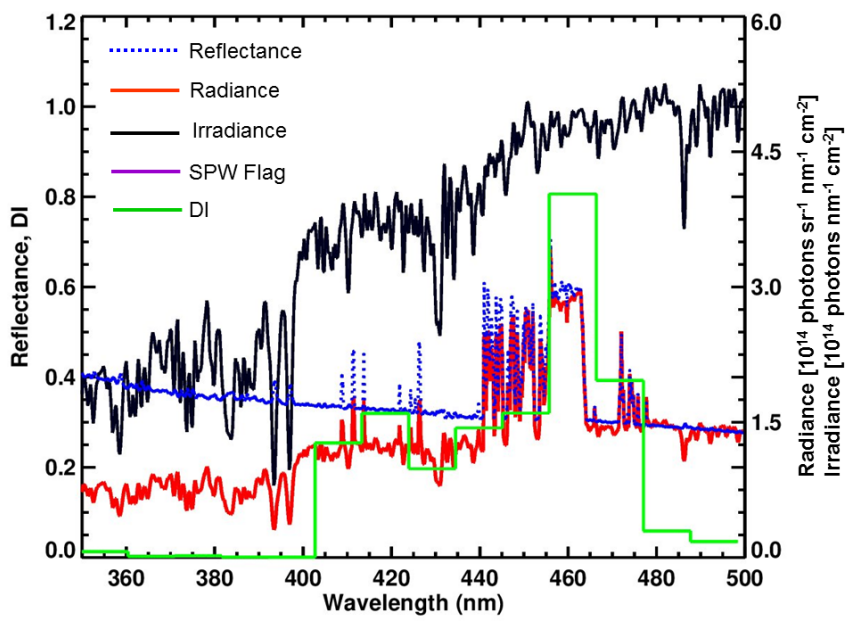

Figure 6. Similar to Fig. 5 but for pixel iTimes 823, row 11, orbit 7987 (see arrows in Fig. 4d). SPW flags are zero for this case and are not shown. 

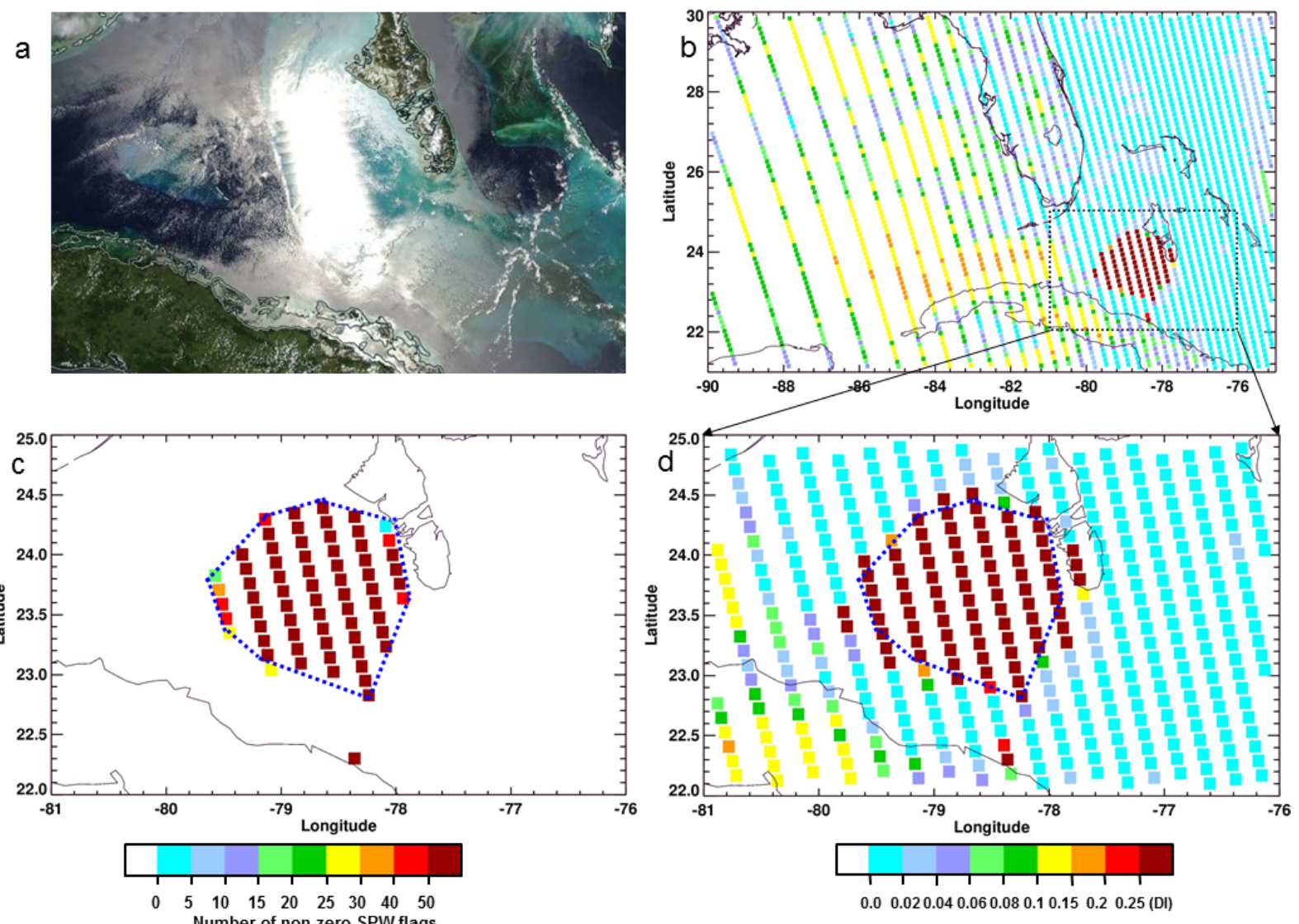

Figure 7. Similar to Fig. 1 but for an area showing solar glint near the Bahamas (orbit 48034, 26 July 2013). Glint positions in panels (c) and (d) do not exactly match those in the RGB image (a). The area of pixels marked by the SPW flags are approximately delineated by the dotted blue line.

sistent with EPIC/DSCOVR data showing solar glint from clouds that contain oriented ice plates (Varnai et al., 2019). In the OMI case, the strongly saturated (or damaged) spectra with DI $>0.60$ occur at a rate of about $2500(\sim 0.0005 \%)$ or $\sim 7$ spectra d $^{-1}$. Slightly affected spectra $(0.25<\mathrm{DI}<0.6)$ occur at a rate of $\sim 0.002 \%$ or $\sim 33$ spectra d $^{-1}$.

\subsection{The row anomaly}

The row anomaly (RA) renders a significant portion of the OMI rows as unusable. The anomaly was clearly detected in two rows in June 2007. In May 2008, the row anomaly spread to several other rows on the sensor. The row anomaly has continued to develop since then, with particularly swift changes around January 2009 and early fall of 2011. Currently, about $33 \%$ of the UV2 rows are affected in the Southern Hemisphere parts of the OMI orbit. This increases to $\sim 57 \%$ in the Northern Hemisphere. These estimates are comparable in the vis channels (Schenkeveld et al., 2017). Figure 11 shows DI distributions in the row versus iTimes format (traditionally used for RA tracking) for the overlapping region of the UV2 and vis detectors. The row anomaly is a complex phenomenon that may result in artificially low or high values of reflectances, additionally affecting their wavelength dependence. The RA stems from an interplay of multiple factors that may affect the DI values. The RA is likely linked to a gradual detachment of the thermal blanket partially blocking some fields of view (FOVs) (rows). Since this blanket is highly reflective, its warped surface causes occasional (solar-angle dependent, predominantly affecting northern portion of the OMI orbit) reflection of the direct sunlight into some RA-affected rows. In addition, the reflective surface leads to enhanced spatial cross-talk between adjacent RA-affected scenes (an anomalous stray light that is regulated by the wavelength- and angle-dependent reflectivity of the blanket). The time-, space- and wavelengthdependent combination of three factors may lead to increasing or decreasing DIs. Even more complications stem from the fact that the RA may increase inhomogeneity of the spectral-slit illumination, thus causing substantial (and unaccounted-for) wavelength shifts and ensuing spectral distortions in the reflectances.

Deciphering the complex RA-related patterns in Fig. 11, we first of all relate them to the pre-RA epoch that shows 


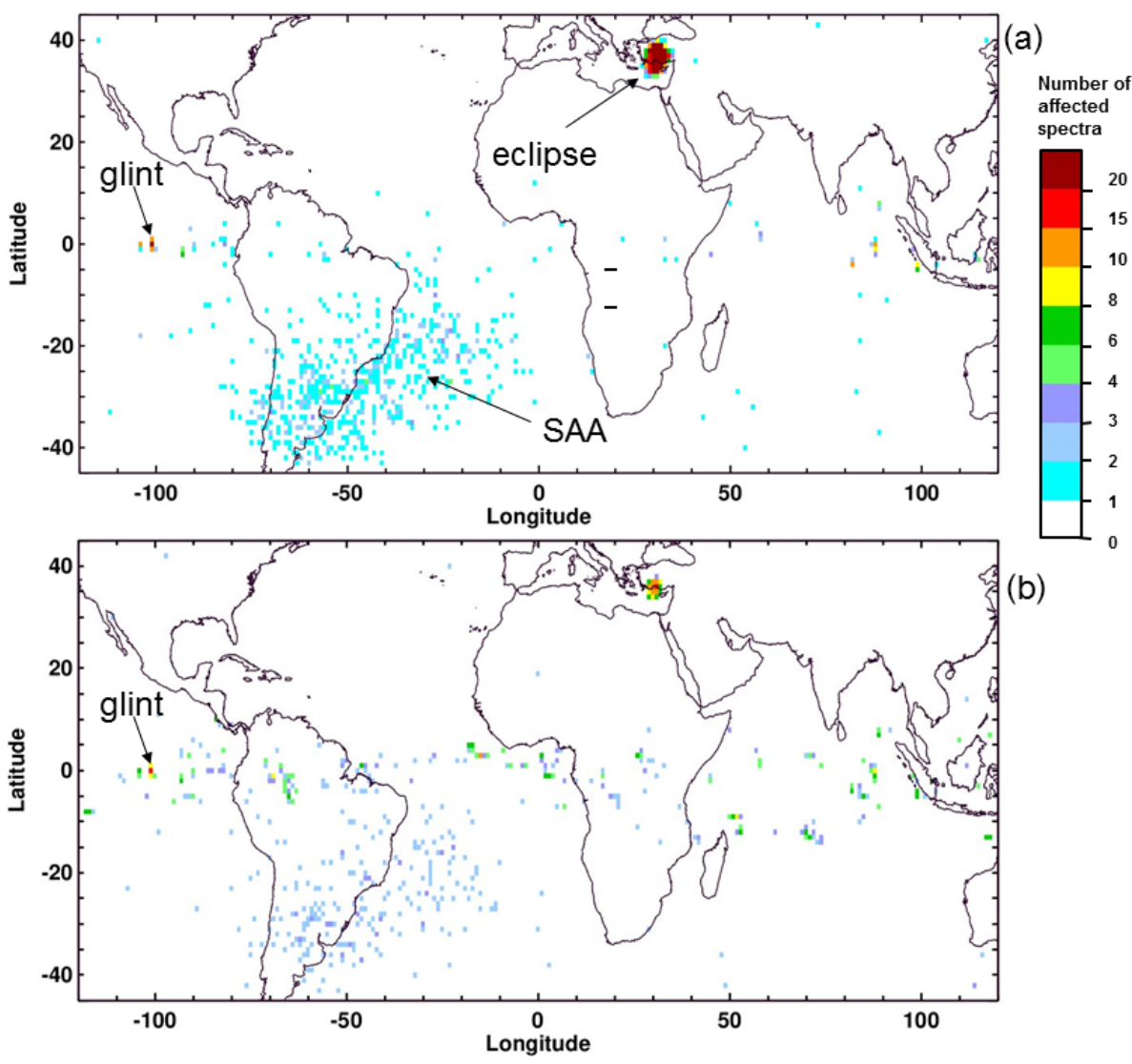

Figure 8. Gridded $\left(1^{\circ} \times 1^{\circ}\right)$ distributions of the number of affected spectra for March 2006; (a) vis of 424.1-434.5 nm, DI >0.03; (b) vis of 445.3-455.7 nm, DI > 0.25. The South Atlantic Anomaly and a region affected by solar eclipse are clearly visible; the remaining pixels with high DI values are mostly associated with sunglint and bright clouds.

an increase in the above-threshold cases in the equatorial regions, with a pronounced minimum centered on the sunglint domain (rows $10-30$ and iTimes $\sim 650-1000$ ). At the same time, the numbers of the above-threshold cases diminish towards the higher latitudes and OMI's swath edges. In the TOA reflectances coming from the sunglint areas, the higher proportion of the directly reflected sunlight leads to a higher radiance-irradiance correlation and thus lower DIs. The latitudinal and swath-angle-dependent trends can be linked to the gradually diminished influence of the surface that modulates the TOA reflectances due to the wavelength-dependent surface albedos. In the planned upgrade of the DI algorithm, we intend to address this component, thus decreasing the impact of geophysical factors.

Turning our attention to the RA-affected areas in Fig. 11, we notice that DIs closely delineate the RA-affected areas and show pronounced north-south asymmetry, with intricate patterns of the relatively higher or lower DIs compared to the RA-free plots. The north-south asymmetry is caused by the well-documented northward growth (Schenkeveld et al., 2017) of the blanket-reflected direct-sunlight component in the RA-affected radiances. This inevitably lessens the cor- responding DIs. The solar influence appears to be strongly cross-swath modulated. This is a new aspect that requires a detailed follow-up study that is beyond the scope of the paper. At the same time, the remainder of the RA-affected areas show significant increase in the above-threshold DIs. This likely comes from the RA-imposed and unaccountedfor wavelength shifts.

The lower DI counts in the sunglint areas in Fig. 11 seemingly contrast with the increased DI values at the center of these regions in the vis (Fig. 10). One should note that Figs. 10 and 11 sample different spectral domains, with the 445.3-455.7 nm range (Fig. 10) known to be highly susceptible to saturation, contrary to the exceedingly rare incidence of saturation in the 349.9-360.3 nm band (Fig. 11).

\section{Discussion and conclusions}

The OMI pixel quality flags (PQFs) were designed to characterize each wavelength of the OMI spectrum (SPW flag is just one of the 16 bits in the PQF). The DI, developed on the basis of the correlations between observed and solar spectra, can serve as a simple but effective and complementary 

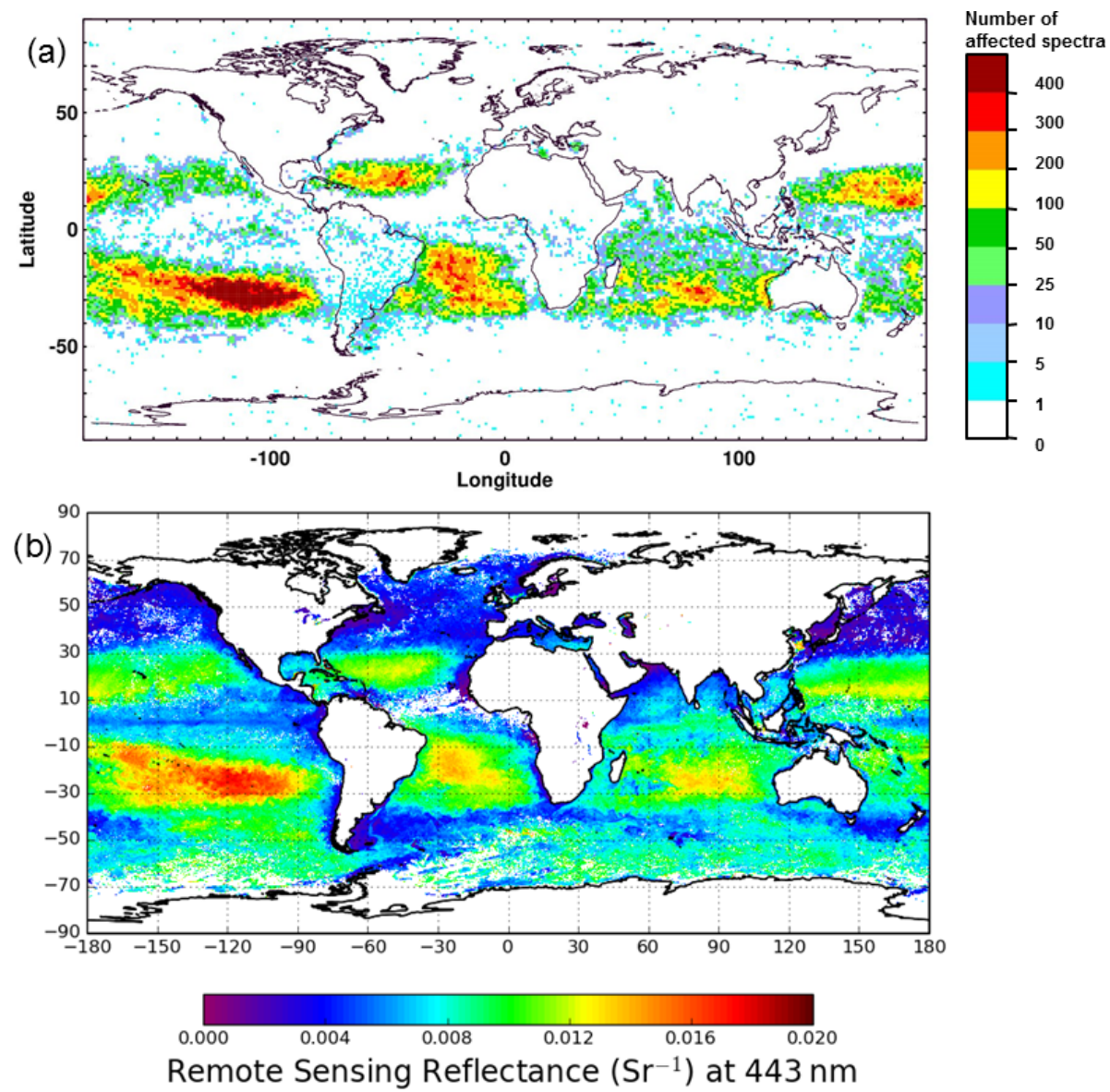

Figure 9. (a) Gridded $\left(1^{\circ} \times 1^{\circ}\right)$ distribution of a number of spectra with DI $>0.1$ for vis of 445.3-455.7 nm in March 2006; (b) ocean remote sensing reflectance for March 2006 at $443 \mathrm{~nm}$ from Aqua MODIS.
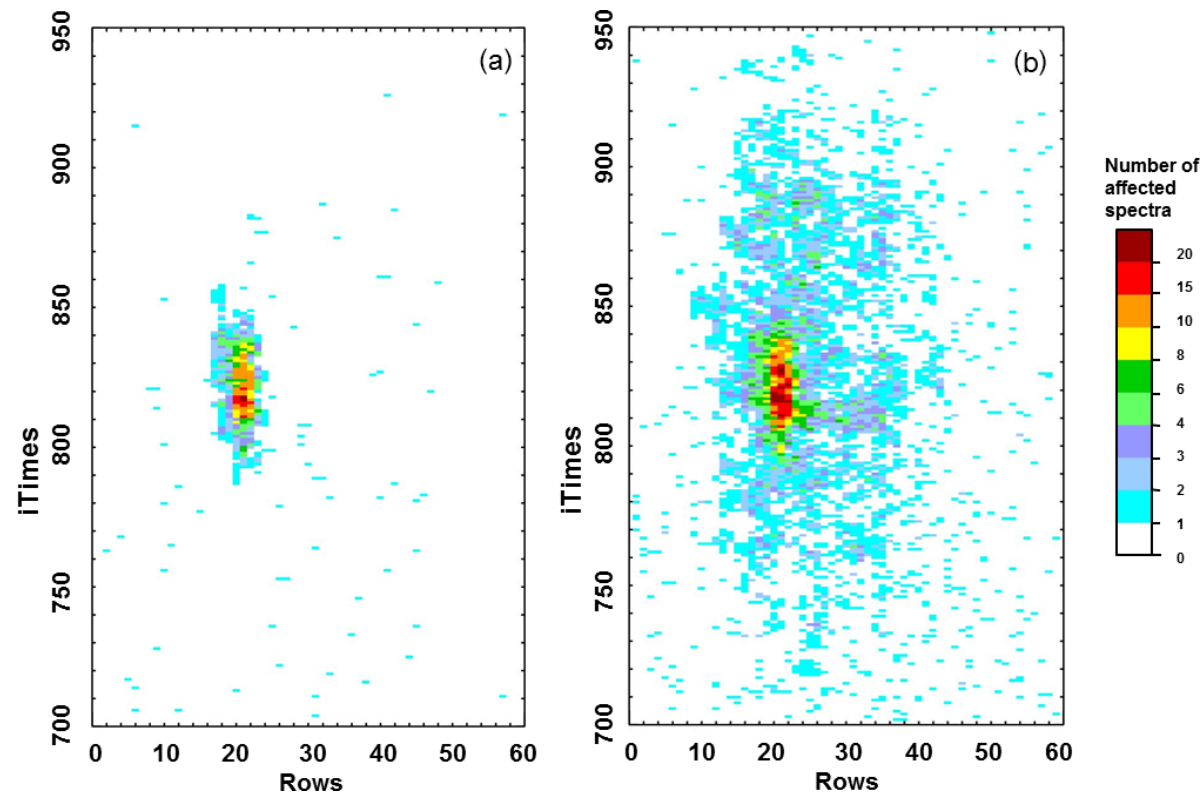

Figure 10. Distribution of a number of affected spectra for 2006, vis of 445.3-455.7 nm; (a) DI $>0.6$; (b) DI $>0.25$. Usually each pixel collects $\sim 5000$ spectra per year. 

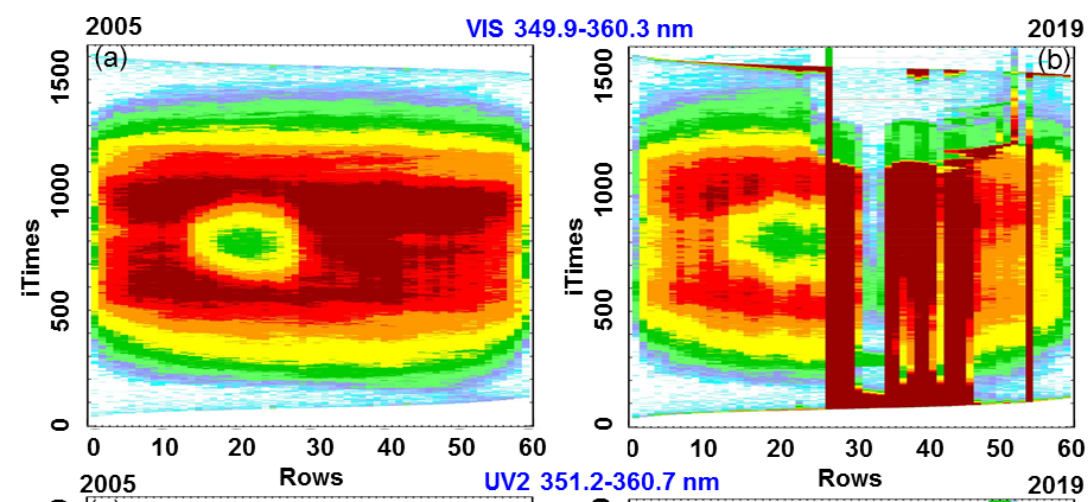

2019
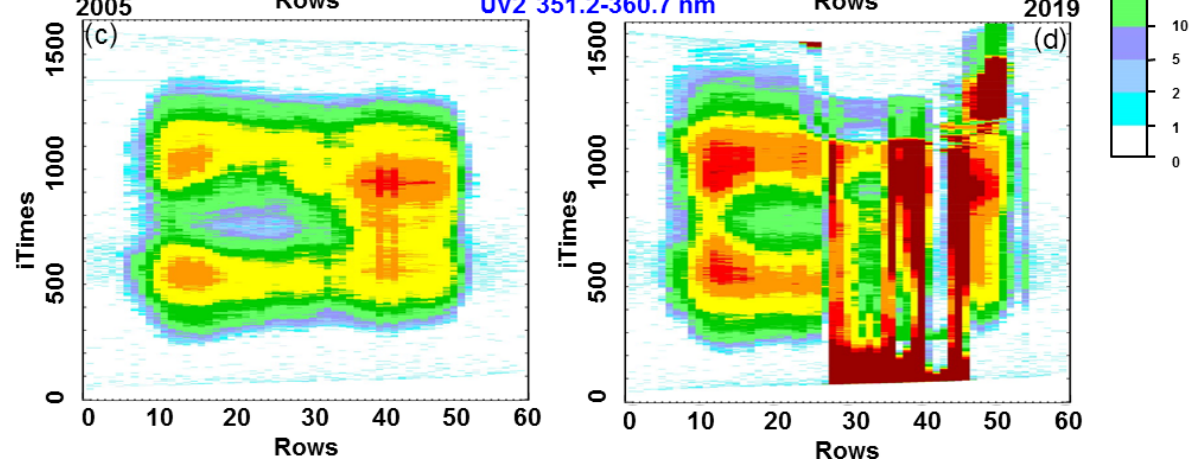

Figure 11. Distribution of the number of affected spectra (DI > 0.01) for March 2005 (a, c) and 2019 (b, d) for vis of 349.9-360.3 nm (a, b) and UV2 of 351.2-360.7 nm (c, d). The row anomaly is responsible for the stripes of high values shown in 2019.

method for detecting and discarding anomalous UV and vis satellite spectra, for example, associated with detector saturation, blooming, charge transfer or readout, excessive noise, cases of very low reflectance such as solar eclipse or the OMI row anomaly. The DI summarizes all changes in the spectrum in one parameter and eliminates the need to examine all the available flags for a given pixel. An important motivation for introducing such an index is the convenience of handling it. For example, to infer enhanced information of the quality of spectra in the vis region, we introduce 14 scalar-valued DIs for regions of the spectrum. For comparison, there are 751 binary saturation flags per spectrum in level 1b. Similarly, we use six DIs for the UV2 spectrum, much fewer than the 577 flags assigned in level 1b. Interpreting a large number of flags can be difficult. The DI product gives an indication of spectral quality based on overall correlation that is easier to interpret. Assessment of the DI with the OMI Collection 3 L1b record has motivated improvements in detector corrections for the next version of the L1b product to be released in OMI Collection 4. The continuous nature of the DI allows data users to assign lower confidence to regions of the spectra that may not be completely saturated as detected by an electronic saturation algorithm. DI values vary for spectra that do not experience any anomalies. These variations of the DI may carry information that can be used for other purposes. For instance, the DI can be used to search for areas of clear ocean water, in which the spectra are not abnormal but expe- rience significant deviations from the solar spectrum due to geophysical reasons.

The DI can be a useful tool for analyzing spectra obtained from other current and future space-borne sensors that may suffer from saturation and blooming such as TROPOMI (launched in 2017) or the similar Environmental trace gases Monitoring Instrument (EMI) on the GaoFen-5 satellite (Cheng et al., 2019; Ren et al., 2020) (launched in 2018). Similar sensors include the OCO-2 (launched in 2014) and OCO-3 (launched in 2019) (Eldering et al., 2019), South Korea's geostationary Environment Monitoring Spectrometer (GEMS) (launched 18 February 2020), NASA's geostationary Tropospheric Emissions: Monitoring of Pollution (TEMPO) (Zoogman et al., 2017) (planned for launch in 2022), the Copernicus geostationary Sentinel-4 (planned for launch in 2023) and low-Earth-orbit Sentinel-5 (planned for launch in 2023). Many of these sensors have a smaller pixel size and/or smaller FOV than OMI. For such instruments, this may lead to an increase in the effects of sunglint. Studies utilizing the DI with current instruments may benefit the design of future instruments by identifying how often and under what conditions spectra are impacted by non-linear effects.

Data availability. The decorrelation index data for OMI Collection 3 data will be available at the NASA Goddard Earth Sciences Data and Information Services Center (GES DISC). The OMI level-1b data used for calculations of the DI are 
available at https://doi.org/10.5067/Aura/OMI/DATA1004 (Dobber, 2007a) and https://doi.org/10.5067/Aura/OMI/DATA1002 (Dobber, 2007b). MODIS data are available at https://doi.org/10.5067/MODIS/MYD09.006 (Vermote, 2015).

Author contributions. NG developed computer codes, analyzed the DI results and wrote the manuscript. ZF supported the development and implementation of the algorithms and comparison DI results with the ocean reflectance. DH proposed a concept of DI and wrote the manuscript. SM proposed a concept of DI and supported the development and implementation of the algorithms. JJ set the task of developing an effective method for determining solar glints, supported the development of the algorithm and wrote the manuscript. AV supported the development of the algorithm and wrote the manuscript.

Competing interests. The authors declare that they have no conflict of interest.

Acknowledgements. The authors thank the OMI and MODIS instrument teams for providing the OMI and MODIS data presented, respectively. We acknowledge the use of imagery from the NASA Worldview application, part of the NASA Earth Observing System Data and Information System (EOSDIS).

We dedicate this work to the memory of Remco Braak, whose early work on saturation in OMI spectra helped to motivate this work.

Financial support. This research has been supported by the NASA Aura project (OMI core team funding) managed by Ken Jucks.

Review statement. This paper was edited by Alexander Kokhanovsky and reviewed by two anonymous referees.

\section{References}

Butz, A., Guerlet, S., Hasekamp, O. P., Kuze, A., and Suto, H.: Using ocean-glint scattered sunlight as a diagnostic tool for satellite remote sensing of greenhouse gases, Atmos. Meas. Tech., 6, 2509-2520, https://doi.org/10.5194/amt-6-2509-2013, 2013.

Cao, X., Hu, Y., Zhu, X., Shi, F., Zhuo, L., and Chen, J.: A simple self-adjusting model for correcting the blooming effects in DMSP-OLS nighttime light images, Remote Sens. Environ., 224, 401-411, https://doi.org/10.1016/j.rse.2019.02.019, 2019.

Chan Miller, C., Gonzalez Abad, G., Wang, H., Liu, X., Kurosu, T., Jacob, D. J., and Chance, K.: Glyoxal retrieval from the Ozone Monitoring Instrument, Atmos. Meas. Tech., 7, 38913907, https://doi.org/10.5194/amt-7-3891-2014, 2014.

Cheng, L., Tao, J., Valks, P., Yu, Ch., Liu, S., Wang, Y., Xiong, X., Wang, Z., and Chen, L.: $\mathrm{NO}_{2}$ retrieval from the Environmental trace gases Monitoring Instrument (EMI): preliminary results and intercomparison with OMI and TROPOMI, Remote Sens.Basel, 11, 3017, https://doi.org/10.3390/rs11243017, 2019.

Cox, C. and Munk, W.: Measurement of the roughness of the sea surface from photographs of the Sun's glitter, J. Opt. Soc. Am., 44, 838-850, https://doi.org/10.1364/JOSA.44.000838, 1954.

Crisp, D., Pollock, H. R., Rosenberg, R., Chapsky, L., Lee, R. A. M., Oyafuso, F. A., Frankenberg, C., O’Dell, C. W., Bruegge, C. J., Doran, G. B., Eldering, A., Fisher, B. M., Fu, D., Gunson, M. R., Mandrake, L., Osterman, G. B., Schwandner, F. M., Sun, K., Taylor, T. E., Wennberg, P. O., and Wunch, D.: The on-orbit performance of the Orbiting Carbon Observatory-2 (OCO-2) instrument and its radiometrically calibrated products, Atmos. Meas. Tech., 10, 59-81, https://doi.org/10.5194/amt-10-59-2017, 2017.

Dobber, M.: OMI/Aura Level 1B VIS Global Geolocated Earth Shine Radiances 1-orbit L2 Swath 13x24 km V003, Greenbelt, MD, USA, Goddard Earth Sciences Data and Information Services Center (GES DISC), https://doi.org/10.5067/Aura/OMI/DATA1004, 2007a.

Dobber, M.: OMI/Aura Level 1B UV Global Geolocated Earthshine Radiances 1-orbit L2 Swath 13×24 km V003, Greenbelt, MD, USA, Goddard Earth Sciences Data and Information Services Center (GES DISC), https://doi.org/10.5067/Aura/OMI/DATA1002, $2007 \mathrm{~b}$.

Dobber, M. R., Dirksen, R. J., Levelt, P. F., van den Oord, G. H. J., Voors, R. H. M., Kleipool, Q., Jaross, G., Kowalewski, M., Hilsenrath, E., Leppelmeier, G. W., de Vries, J., Dierssen, W., and Rozemeijer, N. C.: Ozone Monitoring Instrument calibration, IEEE T. Geosci. Remote, 44, 1209-1238, https://doi.org/10.1109/TGRS.2006.869987, 2006.

Eldering, A., Taylor, T. E., O'Dell, C. W., and Pavlick, R.: The OCO-3 mission: measurement objectives and expected performance based on 1 year of simulated data, Atmos. Meas. Tech., 12, 2341-2370, https://doi.org/10.5194/amt-122341-2019, 2019.

Feng, L., Hu, C., Barnes, B. B., Mannino, A., Heidinger, A. K., Strabala, K., and Iraci, L. T.: Cloud and Sun-glint statistics derived from GOES and MODIS observations over the Intra-Americas Sea for GEO-CAPE mission planning, J. Geophys. Res.-Atmos., 122, 1725-1745, https://doi.org/10.1002/2016JD025372, 2017.

Fricker, H. A., Borsa, A., Minster, B., Carabajal, C., Quinn, K., and Bills., B.: Assessment of ICESat performance at the Salar de Uyuni, Bolivia, Geophys. Res. Lett., 32, L21S06, https://doi.org/10.1029/2005GL023423, 2005.

GDPS: Input/Output Data Specification (IODS) v. 2, Level 1B Output product and Metadata, SDOMIE-7200-DS-467, 44-45, 25 August 2006, available at: https://manualzz.com/doc/28490086/ gdps-input-output-data-specification--iods--volume-2-leve (last access: 2 February 2021), 2006.

Hassinen, S., Tamminen, J., Tanskanen, A., Leppelmeier, G., Mälkki, A., Koskela, T., Karhu, J. M., Lakkala, K., Veefkind, P., Krotkov, N., and Aulamo, O.: Description and validation of the OMI very fast delivery products, J. Geophys. Res., 113, D16S35, https://doi.org/10.1029/2007JD008784, 2008.

Joiner, J., Bhartia, P. K., Cebula, R. P., Hilsenrath, E., McPeters, R. D., and Park, H.: Rotational Raman scattering (Ring effect) in satellite backscatter ultraviolet measurements, Appl. Opt., 34, 4513-4525, https://doi.org/10.1364/AO.34.004513, 1995. 
Kay, S., Hedley, J. D., and Lavender, S.: Sun glint correction of high and low spatial resolution images of aquatic scenes: a review of methods for visible and near-Infrared wavelengths, Remote Sens., 1, 697-730, https://doi.org/10.3390/rs1040697, 2009.

Krotkov, N. A., Li, C., and Leonard, P.: OMI/Aura sulphur dioxide $\left(\mathrm{SO}_{2}\right)$ total column $\mathrm{L} 31 \mathrm{~d}$ best pixel in $0.25^{\circ} \times 0.25^{\circ} \mathrm{V} 3$, Goddard Earth Sciences Data and Information Services Center (GES DISC), Greenbelt, USA, https://doi.org/10.5067/Aura/OMI/DATA3008, 2015.

Lamparelli, R. A. C., Ponzoni, F. J., Zullo, J., Pellegrino G. Q., and Arnaud, Y.: Characterization of the Salar de Uyuni for in-orbit satellite calibration, IEEE T. Geosci. Remote, 41, 1461-1468, https://doi.org/10.1109/TGRS.2003.810713, 2003.

Levelt, P. F. (Ed.): OMI instrument description and level 1B product, ATBD-OMI-01, 1 August 2002, available at: https://eospso. nasa.gov/sites/default/files/atbd/ATBD-OMI-01.pdf (last access: 2 February 2021), 2002.

Levelt, P. F., Joiner, J., Tamminen, J., Veefkind, J. P., Bhartia, P. K., Stein Zweers, D. C., Duncan, B. N., Streets, D. G., Eskes, H., van $\operatorname{der}$ A, R., McLinden, C., Fioletov, V., Carn, S., de Laat, J., DeLand, M., Marchenko, S., McPeters, R., Ziemke, J., Fu, D., Liu, X., Pickering, K., Apituley, A., González Abad, G., Arola, A., Boersma, F., Chan Miller, C., Chance, K., de Graaf, M., Hakkarainen, J., Hassinen, S., Ialongo, I., Kleipool, Q., Krotkov, N., Li, C., Lamsal, L., Newman, P., Nowlan, C., Suleiman, R., Tilstra, L. G., Torres, O., Wang, H., and Wargan, K.: The Ozone Monitoring Instrument: overview of 14 years in space, Atmos. Chem. Phys., 18, 5699-5745, https://doi.org/10.5194/acp18-5699-2018, 2018.

Ludewig, A., Loots, E., Bartstra, R., Landzaat, R., Rozemeijer, N., Vonk, F., Leloux, J., van de Sluis, E., van der Plas, E., Harel, R., van Kempen, T., Tol, P., van Hees, R., and Kleipool, Q.: Level 1b product status/Sentinel-5 Precursor Validation Team Workshop, ESRIN, Frascati, Italy, 11/14 November 2019.

Marchenko, S. and Deland, M.: Solar spectral irradiance changes during cycle 24, Astrophys. J., 789, 117-134, https://doi.org/10.1088/0004-637X/789/2/117, 2014.

Ren, K., Sun, W., Meng, X., Yang, G., and Du, Q.: Fusing China GF-5 Hyperspectral Data with GF-1, GF-2 and Sentinel-2A Multispectral Data: Which Methods Should Be Used?, Remote Sens., 12, 882, https://doi.org/10.3390/rs12050882, 2020.

Richter, A., Hilboll, A., Sanders, A., and Burrows, J. P.: Inhomogeneous scene effects in OMI and TROPOMI satellite data, OMITROPOMI Workshop, convened on-line, 26-29 October 2020, De Bilt, the Netherlands, 2020.

Rozemeijer, N. C. and Kleipool, Q.: S5P Mission Performance Centre, Level 1b Readme, S5P-MPC-KNMI-PRF-L1B, 201908-05, available at: https://sentinel.esa.int/documents/247904/ 3541451/Sentinel-5P-Level-1b-Product-Readme-File (last access: 2 February 2021), 2019.

Schenkeveld, V. M. E., Jaross, G., Marchenko, S., Haffner, D., Kleipool, Q. L., Rozemeijer, N. C., Veefkind, J. P., and Levelt, P. F.: In-flight performance of the Ozone Monitoring Instrument, Atmos. Meas. Tech., 10, 1957-1986, https://doi.org/10.5194/amt-10-1957-2017, 2017.
Sellitto, P., Bojkov, B. R., Liu, X., Chance, K., and Del Frate, F.: Tropospheric ozone column retrieval at northern mid-latitudes from the Ozone Monitoring Instrument by means of a neural network algorithm, Atmos. Meas. Tech., 4, 2375-2388, https://doi.org/10.5194/amt-4-2375-2011, 2011.

Shen, Z., Zhu, X., Cao, X., and Chen, J.: Measurement of blooming effect of DMSP-OLS nighttime light data based on NPP-VIIRS data, Ann. GIS, 25, 153-165, https://doi.org/10.1080/19475683.2019.1570336, 2019.

Singh, R. K. and Shanmugam, P.: A robust method for removal of glint effects from satellite ocean colour imagery, Ocean Sci. Discuss., 11, 2791-2829, https://doi.org/10.5194/osd-11-27912014, 2014.

Tedetti, M., Sempere, R., Vasilkov, A., Charriere, B., Nerini, D., Miller, W. L., Rawamura, K., and Raimbault. P.: High penetration of ultraviolet radiation in the south east Pacific waters, Geophys. Res. Lett., 34, L12610, https://doi.org/10.1029/2007GL029823, 2007.

Varnai, T., Kostinski, A. B., and Marshak, A.: Deep Space Observations of sun glints from marine ice clouds, IEEE Geosci. Remote S., 17, 735-739, https://doi.org/10.1109/LGRS.2019.2930866, 2019.

Vasilkov, A. P., Joiner, J., Gleason, J. F., and Bhartia, P. K.: Ocean Raman scattering in satellite backscatter ultraviolet measurements, Geophys. Res. Lett., 29, 1837-1840, https://doi.org/10.1029/2002GL014955, 2002.

Vermote, E.: MYD09 MODIS/Aqua L2 Surface Reflectance, 5-Min Swath $250 \mathrm{~m}, 500 \mathrm{~m}$, and $1 \mathrm{~km}$. NASA LP DAAC. NASA GSFC and MODAPS SIPS - NASA, https://doi.org/10.5067/MODIS/MYD09.006, 2015.

Westberry, T. K., Boss, E., and Lee, Z.: Influence of Raman scattering on ocean color inversion models, Appl. Opt., 52, 5552-5561, https://doi.org/10.1364/AO.52.005552, 2013.

Ziemke, J. R., Strode, S. A., Douglass, A. R., Joiner, J., Vasilkov, A., Oman, L. D., Liu, J., Strahan, S. E., Bhartia, P. K., and Haffner, D. P.: A cloud-ozone data product from Aura OMI and MLS satellite measurements, Atmos. Meas. Tech., 10, 40674078, https://doi.org/10.5194/amt-10-4067-2017, 2017.

Zoogman, P., Liu, X., Suleiman, R. M., Pennington, W. F., Flittner, D. E., Al-Saadi, J. A., Hilton, B. B., Nicks, D. K., Newchurch, M. J., Carr, J. L., Janz, S. J., Andraschko, M. R., Arola, A., Baker, B. D., Canova, B. P., Chan Miller, C., Cohen, R. C., Davis, J. E., Dussault, M. E., Edwards, D. P., Fishman, J., Ghulam, A., González Abad, G., Grutter, M., Herman, J. R., Houck, J., Jacob, D. J., Joiner, J., Kerridge, B. J., Kim, J., Krotkov, N. A., Lamsal, L., Li, C., Lindfors, A., Martin, R. V., McElroy, C. T., McLinden, C., Natraj, V., Neil, D. O., Nowlan, C. R., O’Sullivan, E. J., Palmer, P. I., Pierce, R. B., Pippin, M. R., Saiz-Lopez, A., Spurr, R. J. D., Szykman, J. J., Torres, O., Veefkind, J. P., Veihelmann, B., Wang, H., Wang, J., and Chance, K.: Tropospheric emissions: monitoring of pollution (TEMPO), J. Quant. Spectrosc. Ra., 186, 17-39, https://doi.org/10.1016/j.jqsrt.2016.05.008, 2017. 